\title{
Petrology of the Nyiragongo volcano, DR Congo
}

\author{
SANDER MARTIJN MOLENDIJK ${ }^{1}$, OLIVIER NAMUR ${ }^{2}$, \\ PAUL R. D. MASON ${ }^{3}$, BENOÎT SMETS ${ }^{4,5}$, JACQUELINE \\ VANDER AUWERA $^{6}$ AND DAVID A NEAVE ${ }^{7}$
}

\author{
${ }^{1}$ KU Leuven \\ ${ }^{2}$ Katholieke Universiteit, Leuven \\ ${ }^{3}$ Utrecht University \\ ${ }^{4}$ Royal Museum of Central Africa \\ ${ }^{5}$ Vrije Universiteit Brussel \\ ${ }^{6}$ University of Liege \\ ${ }^{7}$ The University of Manchester
}

Presenting Author: sander.molendijk@kuleuven.be

The Nyiragongo volcano is one of the most alkali-rich magmatic systems on the planet, currently characterized by the presence of a persistent lava lake in the summit crater which hosts silica-undersaturated $\left(\mathrm{SiO}_{2}<40 \mathrm{wt} . \%\right)$, low viscosity lavas with a significantly elevated alkali content $\left(\mathrm{Na}_{2} \mathrm{O}+\mathrm{K}_{2} \mathrm{O}>10\right.$ wt.\%).

In order to better understand this exotic magmatic system, we present a set of 244 samples of the Nyiragongo volcano, acquired during a field expedition performed in 2017. Lithologies range from primitive picrites $(\mathrm{Mg \#} \mathrm{82)}$ erupted by parasitic cones to a variety of highly evolved nephelinites, leucitites, and melilitites erupted from the main edifice as recently as 2016.

Extensive mineralogical characterisation in terms of major and trace element geochemistry is presented for the full lithological diversity of Nyiragongo, revealing a compositional range in olivine from forsteritic $(\mathrm{Fo}=91)$ to Ca-rich $(\mathrm{Fo}=2,31 \mathrm{wt} . \%$ $\mathrm{CaO}$ ). Similarly, clinopyroxene crystals cover a compositional range of $\mathrm{Mg} \#=89$ to $\mathrm{Mg} \#=2$. Melilite is dominantly alumoåkermanitic, with only minor compositional variation driven by $\mathrm{Ca}-\mathrm{Na}$ substitution, and additionally acts as a carrier of $\mathrm{Sr}$ and Ba.

Trace element patterns indicate significant enrichment (up to $100 *$ E-MORB concentrations) of LREE and LILE increasing with fractionation, coinciding with comparative depletions in HFSE.

Primitive olivine trace elemental compositions and associated melt-inclusion chemistries will be discussed in order to identify the significant chemical disparity between parasitic cone- and main-crater products, and shed light on the mantle source from which these are derived. 